\title{
The International GNSS Service in a changing landscape of Global Navigation Satellite Systems
}

\author{
John M. Dow • R. E. Neilan - C. Rizos
}

Received: 15 December 2008 / Accepted: 17 December 2008

(C) Springer-Verlag 2009

\begin{abstract}
The International GNSS Service (IGS) is an international activity involving more than 200 participating organisations in over 80 countries with a track record of one and a half decades of successful operations. The IGS is a service of the International Association of Geodesy (IAG). It primarily supports scientific research based on highly precise and accurate Earth observations using the technologies of Global Navigation Satellite Systems (GNSS), primarily the US Global Positioning System (GPS). The mission of the IGS is "to provide the highest-quality GNSS data and products in support of the terrestrial reference frame, Earth rotation, Earth observation and research, positioning, navigation and timing and other applications that benefit society". The IGS will continue to support the IAG's initiative to coordinate cross-technique global geodesy for the next decade, via the development of the Global Geodetic Observing System (GGOS), which focuses on the needs of global geodesy at the mm-level. IGS activities are fundamental to scientific disciplines related to climate, weather, sea level change, and space weather. The IGS also supports many other applications, including precise navigation, machine automation, and surveying and mapping. This article discusses the IGS Strategic Plan and future directions of the globally-coordinated $\sim 400$ station IGS network, tracking data and information products, and outlines the scope of a few of its numerous
\end{abstract}

\author{
J. M. Dow $(\varangle)$ \\ ESA/ESOC, Darmstadt, Germany \\ e-mail: john.dow@esa.int \\ R. E. Neilan \\ NASA/JPL, Pasadena, USA \\ C. Rizos \\ School of Surveying and Spatial Information Systems, \\ University of New South Wales, Sydney, Australia
}

working groups and pilot projects as the world anticipates a truly multi-system GNSS in the coming decade.

\section{Introduction}

The International GNSS Service (IGS) was officially established in January 1994 as a service of the International Association of Geodesy (IAG 2008). Since June 1992, the IGS—originally known as the "International GPS Service for Geodynamics", from 1999 simply the "International GPS Service", and finally since March 2005 the "International GNSS Service"- - has been making freely available to interested users precision GPS satellite orbit and clock corrections and other products, see IGS (2008), Beutler et al. (1999) and Dow et al. (2004, 2005). The origins and early development of the IGS are described by Beutler et al. (2008).

The IGS operates as a voluntary, non-commercial confederation of about 200 institutions world-wide (see Fig. 1 for a map of the global station network), self-governed by its members, managed on a day-to-day basis by the Central Bureau under the policy guidance of the Governing Board. Each participating organisation contributes its own resources: there is no central source of funding.

Since the IGS Governing Board adopted in December 2001 its Strategic Plan, covering the years 2002-2007, a number of developments taking place inside and outside the IGS has made it necessary to revise the plan. A reflection process was initiated at the 2004 Workshop in Bern, Switzerland, continued through a dedicated session at the 2006 Darmstadt Workshop, Germany, culminating in a one and a half day meeting of a specially appointed Strategic Planning Committee in Pasadena, California, in September 2006, and a two day Strategic Planning Retreat of the Governing Board 


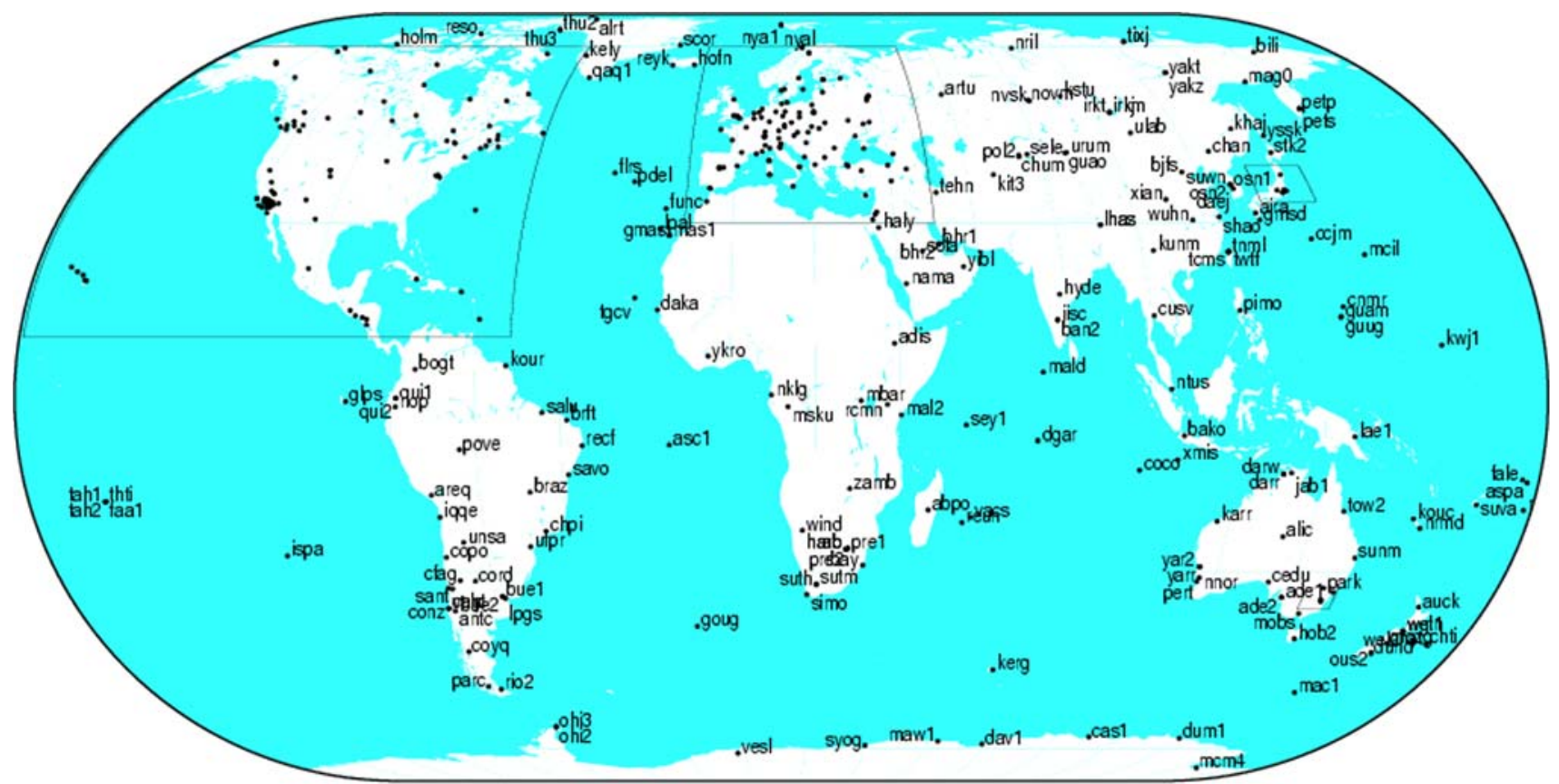

बinग

Fig. 1 Global distribution of stations of the IGS network

in San Francisco in December 2006. A new IGS Strategic Plan for the years 2008-2012 has resulted from this process.

This article outlines some of the current central concerns of the IGS and points to the key issues for the coming years.

\section{The IGS products}

The IGS collects, archives, and distributes GPS and GLONASS observation data sets of sufficient accuracy to meet the objectives of a wide range of scientific and engineering users. These data sets are analysed and combined to form the IGS products shown in Table 1 (IGS 2008).

IGS products support scientific activities such as improving and extending the International Terrestrial Reference Frame (ITRF) maintained by the International Earth Rotation and Reference Systems Service (IERS); monitoring deformations of the solid Earth and variations in the liquid Earth (sea level, ice sheets, etc.) and in Earth rotation; determining orbits of scientific satellites; and monitoring the troposphere and ionosphere.

Typical accuracies and latencies of the various products are indicated in Table 1 . The primary IGS products are the GPS satellites' IGS Final Orbit and Clock corrections, now at the $\mathrm{cm}$ accuracy level (see Fig. 2 for the recent evolution of orbit accuracy). The accuracy of a recent orbit solution, together with some relevant ancillary information, can be seen in Fig. 3.

\section{The changing GNSS landscape}

While the IGS product range has been mainly concerned with GPS, since 1998 GLONASS products were developed, initially in connection with the International GLONASS Experiment (IGEX) of 1999 (Slater et al. 2004). This continued seamlessly, from 2001, through the International GLONASS Service (IGLOS), a pilot project of the IGS, which reached a successful conclusion in December 2005, when the GLONASS products (raw data and derived products) were integrated into the mainstream IGS product flow (see Table 1). The participation during the past 2 years of the Russian Institute IAC in the IGS GLONASS orbit combination has contributed to improvements in the quality of these products. Improvements in the GLONASS geodetic reference frame PZ 90 are in part due to assimilation of IGS stations with coordinates well-determined in the ITRF.

More recently, the IGS has been actively following the development of the European Galileo system, in three general areas (Dow et al. 2007).

First, the IGS GNSS Working Group and its individual members are involved in bringing to the attention of the new GNSS system providers the experience gained over the past decade and a half in the IGS concerning orbit models, antenna phase calibrations, standardisation of data formats and other matters. This applies to future generation GPS as well as to Galileo, and to other systems such as China's Beidou/Compass, India's Regional Navigation Satellite System (IRNSS), and Japan's Quasi-Zenith Satellite System (QZSS). 
Table 1 IGS product summary

\begin{tabular}{|c|c|c|c|c|}
\hline & Accuracy & Latency & Updates & Sample interval \\
\hline \multicolumn{5}{|c|}{ GPS satellite ephemerides/satellite and station clocks } \\
\hline \multicolumn{5}{|c|}{ Broadcast } \\
\hline Orbits & $\sim 160 \mathrm{~cm}$ & \multirow{2}{*}{ Real time } & \multirow{2}{*}{-} & \multirow{2}{*}{ Daily } \\
\hline Sat. clks & $\sim 7 \mathrm{~ns}$ & & & \\
\hline \multicolumn{5}{|l|}{ Ultra-rapid (predicted half) } \\
\hline Orbits & $\sim 10 \mathrm{~cm}$ & \multirow{2}{*}{ Real time } & \multirow{2}{*}{ Four $\times$ daily } & \multirow{2}{*}{$15 \min$} \\
\hline Sat. clks & $\sim 5 \mathrm{~ns}$ & & & \\
\hline \multicolumn{5}{|l|}{ Ultra-rapid (observed half) } \\
\hline Orbits & $<5 \mathrm{~cm}$ & \multirow{2}{*}{$3 \mathrm{~h}$} & \multirow{2}{*}{ Four $\times$ daily } & \multirow{2}{*}{$15 \mathrm{~min}$} \\
\hline Sat. clks & $\sim 0.2 \mathrm{~ns}$ & & & \\
\hline \multicolumn{5}{|l|}{ Rapid } \\
\hline Orbits & $<5 \mathrm{~cm}$ & \multirow{2}{*}{$17 \mathrm{~h}$} & \multirow{2}{*}{ Daily } & $15 \mathrm{~min}$ \\
\hline Sat. and Stn. clks & $0.1 \mathrm{~ns}$ & & & $5 \mathrm{~min}$ \\
\hline \multicolumn{5}{|l|}{ Final } \\
\hline Orbits & $<5 \mathrm{~cm}$ & \multirow{2}{*}{$\sim 13$ days } & \multirow{2}{*}{ Weekly } & $15 \mathrm{~min}$ \\
\hline Sat. and Stn. clks & $<0.1 \mathrm{~ns}$ & & & $5 \mathrm{~min}$ \\
\hline \multicolumn{5}{|l|}{ GLONASS satellite ephemerides } \\
\hline Final & $15 \mathrm{~cm}$ & 2 weeks & Weekly & $15 \mathrm{~min}$ \\
\hline \multicolumn{5}{|c|}{ Geocentric coordinates of IGS Tracking Stations (>130 sites) } \\
\hline \multicolumn{5}{|l|}{ Final positions } \\
\hline Horizontal & $3 \mathrm{~mm}$ & \multirow{2}{*}{12 days } & Weekly & Weekly \\
\hline Vertical & $6 \mathrm{~mm}$ & & & \\
\hline Final velocities & & & & \\
\hline Horizontal & $2 \mathrm{~mm} /$ year & 12 days & Weekly & Weekly \\
\hline Vertical & $3 \mathrm{~mm} /$ year & & & \\
\hline Earth rotation parameters & & & & \\
\hline Ultra-rapid (predicted half) & & & & \\
\hline PM & 0.3 mas & & & \\
\hline PM rate & 0.5 mas/day & Real time & Four $\times$ daily & Four $\times$ daily $(00,06,12,18$ UTC $)$ \\
\hline LOD & $0.06 \mathrm{~ms}$ & & & \\
\hline Ultra-rapid (observed half) & & & & \\
\hline $\mathrm{PM}$ & $0.1 \mathrm{mas}$ & & & \\
\hline PM rate & 0.3 mas/day & $3 \mathrm{~h}$ & Four $\times$ daily & Four $\times$ daily $(00,06,12,18$ UTC $)$ \\
\hline LOD & $0.03 \mathrm{~ms}$ & & & \\
\hline Rapid & & & & \\
\hline PM & $<0.1$ mas & & & \\
\hline PM rate & $<0.2$ mas/day & $17 \mathrm{~h}$ & Daily & Daily (12 UTC) \\
\hline LOD & $0.03 \mathrm{~ms}$ & & & \\
\hline Final & & & & \\
\hline PM & $0.05 \mathrm{mas}$ & & & \\
\hline PM rate & $<0.2 \mathrm{mas} /$ day & $\sim 13$ days & Weekly & Daily (12 UTC) \\
\hline LOD & $0.02 \mathrm{~ms}$ & & & \\
\hline Atmospheric parameters & & & & \\
\hline Final tropospheric zenith path delay & $4 \mathrm{~mm}$ & $<4$ weeks & Weekly & $2 \mathrm{~h}$ \\
\hline Ultra-rapid tropospheric zenith path delay & $6 \mathrm{~mm}$ & $2-3 \mathrm{~h}$ & Every $3 \mathrm{~h}$ & $1 \mathrm{~h}$ \\
\hline Final ionospheric TEC grid & 2-8TECU & $\sim 11$ days & Weekly & $2 \mathrm{~h}, 5 \operatorname{deg}($ lon $) \times 2.5 \operatorname{deg}$ (lat) \\
\hline Rapid ionospheric TEC grid & 2-9TECU & $<24 \mathrm{~h}$ & Daily & $2 \mathrm{~h}, 5 \operatorname{deg}($ lon $) \times 2.5 \mathrm{deg}$ (lat) \\
\hline
\end{tabular}


Fig. 2 Improvement of IGS final orbits with time (since GPS week 700)

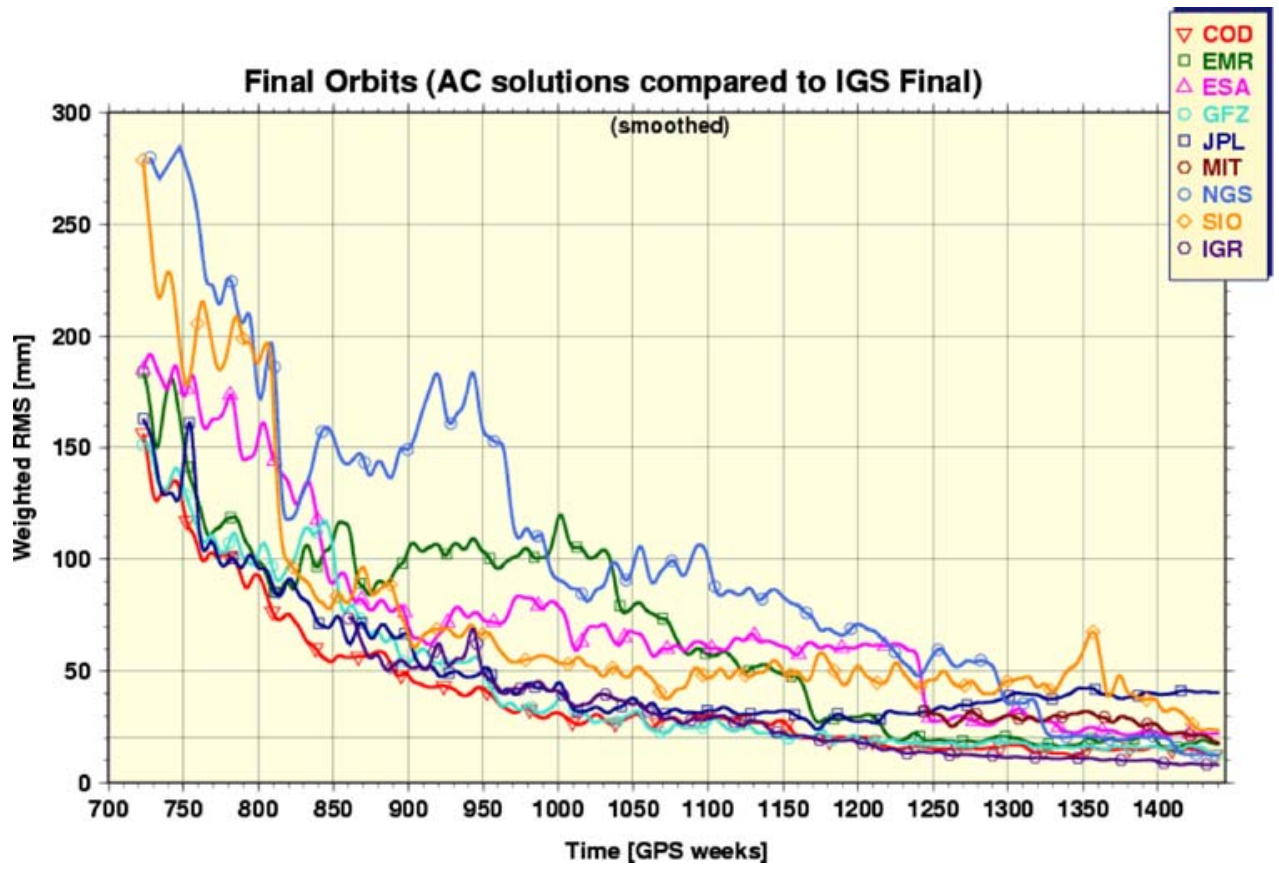

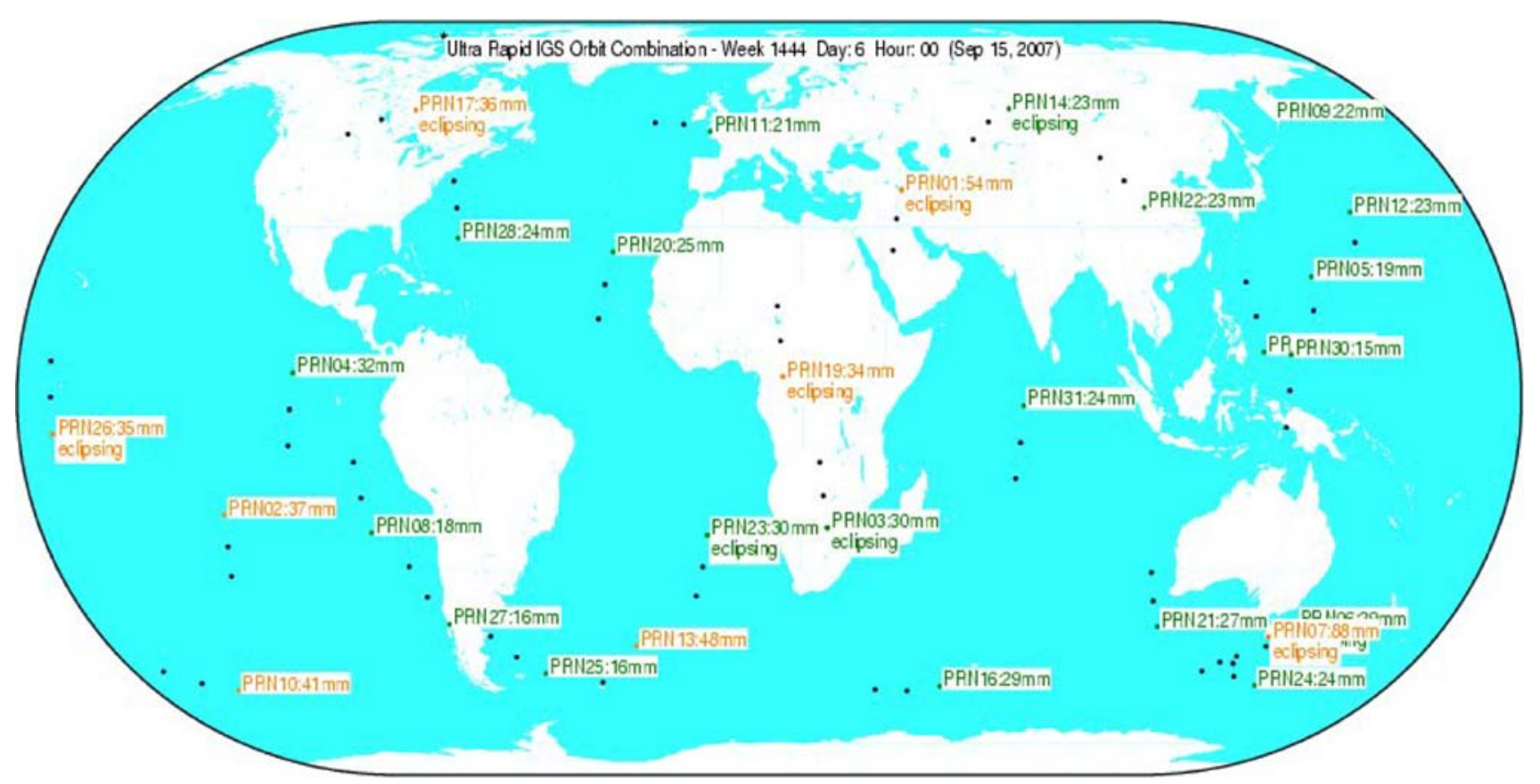

Fig. 3 Accuracy of a typical recent Ultra Rapid IGS orbit combination, by satellite

Second, European IGS participants contributing to the global IGS ground station network (ESOC and GeoForschungsZentrum Potsdam-GFZ) have been working with European industry and ESA to set up and operate the network of sensor stations (GIOVE Experimental Sensor StationsGESS) to track the experimental GIOVE satellites. This network, totalling 13 stations, including 11 on well-tested IGS sites, has been fully operational since early 2007 .
The third area in which IGS has been able to contribute its expertise is in the Galileo Geodetic Service Provider (GGSP) Prototype. This is a project funded by the European GNSS Supervisory Authority (GSA), with technical management support from ESA, with the objective of designing and developing a system capable of providing and maintaining over the projected 20 year lifetime of the Galileo system a geodetic reference frame, to be known as the Galileo Terrestrial 
Reference Frame (GTRF). This frame shall be within $3 \mathrm{~cm}$ (2-sigma) of the ITRF (IERS 2008), to which the IGS contributes on a routine basis the consolidated GPS input. Three European IGS Analysis Centres (University of Bern, GFZ Potsdam, ESA/ESOC), as well as key European institutes involved in the IERS (BKG, IGN), supported by Canadian and Chinese organisations (NRCan, University of Wuhan), are working in a consortium led by the GFZ. A first realisation of the GTRF, based on GPS data from selected IGS sites, has been successfully validated. Updates will be based on inclusion (in addition) of GPS data from the GIOVE network and then GIOVE data itself. As the Galileo Sensor Stations (GSS) planned for the Galileo In-orbit Validation Phase are established, data from those sites will also be processed and included. The GGSP will have an important two-way interface with the Galileo Ground Mission Segment (GMS), to retrieve the necessary GSS data and to provide the resulting reference frame information. It will also provide the interface between the GMS and the International Laser Ranging Service, in order to facilitate provision of satellite laser ranging data for the Galileo spacecraft for calibration purposes. Further details of the GGSP can be found in Gendt et al. (2007).

IGS and IAG representatives are active in the recently established US National Space-based Position Navigation and Timing Advisory Board, which provides to the PNT Executive Committee advice relating to positioning, navigation and timing (PNT) policy and capabilities (PNT 2008).

In addition, the IGS (as well as the IAG and other international and intergovernmental organisations) are members of the International Committee on GNSS (ICG), convened by the U.N. Office of Outer Space Affairs (UNOOSA 2008), see below.

\section{IGS working groups and pilot projects}

The IGS has a number of working groups, focused on different aspects of current GNSS product generation, as well as pilot projects investigating future developments which could lead to the generation of new IGS products. The current WGs are:

- Ionosphere Working Group

- Troposphere Working Group

- IGS Reference Frame Working Group

- Low Earth Orbiter (LEO) Working Group

- Real Time Working Group

- GNSS Working Group

- Data Center Working Group

- Clock Products Working Group

- Calibration and Biases Working Group
The current IGS pilot projects are:

- Tide Gauge Benchmark Monitoring Project for Sea Level Studies (TIGA)

- Real Time Pilot Project

The charter of each WG and PP describes the goals and objectives, see IGS (2008). The chairs of the WGs and PPs report to the IGS Governing Board on a regular basis.

\section{Towards real time products}

The IGS has been developing the capability for real time data streaming from the ground station network for some years. Currently up to 60 stations are providing data, with a latency of the order of a few seconds (IGSRT 2008). A recent development was the initiation of a Real Time Pilot Project (RT-PP), which has the following objectives:

- Manage and maintain a global IGS real time GNSS tracking network.

- Enhance and improve selected IGS products.

- Generate new real time products.

- Investigate standards and formats for real time data collection, data dissemination and delivery of derived products. Both the RTIGS and the NTRIP protocols will be assessed as to their suitability.

- Monitor the integrity of IGS predicted orbits and GNSS status.

- Distribute observations and derived products to real time users, and support Network DGPS/RTK operations.

- Encourage cooperation among real time activities, particularly in IGS densification areas.

The call for participation in the RT-PP (see IGS 2008) requested proposals for:

- Real time Tracking Stations

- Real time Data Centres

- Real time Analysis Centres

- Real time Associate Analysis Centres

- Real time Analysis Centre Coordinator

- Real time Network Management and Monitoring

- Real time Users for Assessment, Evaluation and Feedback

The RT-PP will gather and distribute real time data and products associated with GNSS satellite constellations. The primary products envisioned are multi-frequency observation data and precise satellite clocks and orbits made available in real time. These products will be freely available to participants, and eventually to external users, for any purpose, 
in accordance with the IGS open data policy. An important objective of the RT-PP will be to support and promote the development of real time applications. The IGS will work closely with standards setting bodies such as the RTCM, to ensure appropriate real time capabilities are implemented in the next generation of GNSS receivers. The RT-PP will operate for a period of up to 3 years. Annual reviews will be conducted by the IGS Governing Board to assess the project's progress towards achieving its goals and objectives.

\section{The IGS network}

The IGS may be unique in its commitment to inclusiveness and a vendor-neutral stance toward instrumentation. This permits participation by a wide variety of agencies, universities, and individuals. It also results in a large and heterogeneous network of equipment that presents certain calibration, standardization, and coordination challenges. A typical IGS site consists of a monument, antenna, receiver, an ultra-stable clock (in many cases a hydrogen maser or rubidium or cesium atomic clock) and optionally a computer and communications device. The monument is the stable connection of the antenna to a point on the ground. Monument types include pillars, braced-rod types, and building mounts. Antennas and receivers from a variety of commercial manufacturers are dual-frequency and record both code and phase from the GPS and optionally GLONASS satellites. Not all types of equipment are suitable for the most demanding precise geophysical applications; more information is available at the IGS station guidelines (IGS 2008). Since IGS stations must return data on a daily basis, they are connected to communications suitable to support this. Internet, telephone, radio, and satellite communications are variously employed according to each site's characteristics. Obviously real time data streaming by stations participating in the RT-PP is a significant communications challenge for some stations.

What are some of the issues facing the IGS tracking network in the context of the "changing landscape" of GNSS? The authors list the following:

- What will be the characteristics of the future IGS-type geodetic receiver? What transmitted signals will it track?

- What is the most suitable station monument for future IGS stations? Need they all be constructed to the highest possible stability standards? Or is it likely that there may be several "tiers" of IGS station types?

- How to define "minimum operational requirements" for IGS stations for an era where the quality of derived IGS products must increase significantly in order to satisfy the goals of GGOS (see below)? Are there generally accepted standards for data quality, or other quality metrics, that can be adhered to?
- How to manage the potentially disruptive process of station upgrade (in particular changes in antenna type) as new receivers, tracking next generation GNSS signals, are progressively installed?

- How to encourage the establishment of more IGS stations in parts of the world where there is currently a lower density? In particular in Africa, Russia, and parts of East and S.E. Asia, with a real time data streaming capability.

- Can there ever be "too many" IGS stations? What station spacing does that correspond to?

- How to best integrate the operations of IGS stations in areas where there are already dense receiver networks, such as the western United States and parts of Europe?

\section{IGS and the Global Geodetic Observing System}

In parallel with these IGS internal developments, the IGS has been working with the IAG on the design of the Global Geodetic Observing System (GGOS 2008), which would integrate the activities and products of the IAG Services and Commissions (IAG 2008) in order to provide the contribution of geodesy to the Global Earth Observing System of Systems (GEOSS) now being established by the inter-governmental Group on Earth Observations (GEO). The ITRF (in particular, its future evolution, and its correct and consistent use) is a central issue of the GGOS initiative. The IGS, with its prime concern for high accuracy and high reliability processing of the signals of the GNSS constellations and as provider of the consolidated inputs of the GNSS contribution to the ITRF, will necessarily play a key role in GGOS.

The work of the IGS and its constituent elements is becoming even more relevant to global societal issues which are driving the need for a better understanding of the "Earth System" in which we live. The IGS, though its participation in the GGOS effort, can contribute in areas such as climate change, global mass transport, sea level rise, measuring surface geodynamics at a range of spatial scales, geohazard prediction and monitoring, and natural disaster mitigation (earthquakes, volcanoes, tsunamis, etc.)

\section{The International Committee on GNSS}

Another recent development is the establishment of the International Committee on GNSS (ICG), which was officially established through the United Nations Office of Outer Space Affairs (UNOOSA) in December 2005, following extensive preparatory meetings and actions over several years in which the IGS played an active role. The members of the ICG are the developers (or "providers") of the GNSS systems and several other interested UN member states, while associate members are mainly inter-governmental and non-governmental organisations representing primarily users of GNSS, such as the IGS, IAG, etc. (UNOOSA 2008). 
Three meetings of the ICG have taken place, the first at the United Nations center in Vienna, Austria, in November 2006, the second in Bangalore, India, in early September 2007, and the third in Pasadena, California, in early December 2008. Significant issues (from the point of view of the IGS) that were discussed included standardisation of geodetic and time reference frames. Three recommendations relevant to these issues were adopted in the final plenary session.

The IGS is thus playing an even more active role in the international context of GNSS. The latter itself is changing rapidly, with further improvements of the GPS system (GPS IIM, GPS IIF, GPS III satellite constellations), the revival of the Russian GLONASS (likely to reach a complete constellation again in the next year or two, with additional system developments on the horizon, including a possible move to CDMA signals), the European Galileo system of 30 satellites, and global or regional systems being developed by Japan, China and India, among others. High on the international agenda is the compatibility and (where possible) interoperability of these systems. The IGS will continue to take an active role in monitoring the progress of these systems, investigating their utility for the highest-quality GNSS products and services, and in providing its experience and expertise, in particular with regards to the support of highaccuracy research and applications based on the analysis of GNSS signals.

The IGS, as a source of independent expertise on matters related to GNSS technology and its application to reference frame definition, will be an important partner in global initiatives such as AFREF. This project seeks to establish a single, high quality geodetic reference frame for the whole of the African continent. In partnership with Africa's national surveying and mapping agencies, and international associations such as the IAG and the International Federation of Surveyors (FIG), the IGS is encouraging the establishment of a network of continuously operating GNSS reference stations across the continent. This network will provide the raw observations which, when processed together with IGS products such as precise GNSS orbits, will underpin all future geospatial data gathering, geoscientific studies and navigation operations in Africa.

\section{The IGS strategic plan 2008-2012}

Although much of the IGS Strategic Plan 2002-2007 remains valid, a new plan was developed during 2006-2007. A mission statement and six long-term goals were formulated.

\subsection{Mission}

The International GNSS Service provides the highest-quality GNSS data and products in support of the terrestrial refer- ence frame, Earth rotation, Earth observation(s) and research, positioning, navigation and timing and other applications that benefit society.

\subsection{Long-term goals}

1. Serve as the premier source of the highest-quality GNSS related standards (conventions), data and products, openly available to all user communities.

2. Attract leading-edge expertise to pursue challenging, innovative projects in a collegial, collaborative and creative culture.

3. Incorporate and integrate new systems, technologies, applications and changing user needs into IGS products and services.

4. Facilitate the integration of IGS into GGOS and other more broadly based earth observing and global navigation systems and services.

5. Maintain an international federation with committed contributions from its members, and with effective leadership, management and governance.

6. Promote the value and benefits of IGS to society, the broader scientific community, and in particular to policy makers and funding entities.

Based on these, the new plan identifies three key strategies:

1. Deliver world-standard quality GNSS data and products to all users globally with leading-edge expertise and resources.

2. Develop, integrate, and participate with new and changing GNSS systems and user needs to continuously improve IGS services and to provide value to a broad range of users.

3. Continuously improve the effectiveness of IGS management and governance to support future growth of the service.

The broad objectives remain unchanged, however a significant number of the derived actions are new. The full plan will be available shortly on the IGS website, as well as in printed form.

The implementation of the Strategic Plan will be aided by the formulation and execution of annual Implementation Plans, in which the principal targets for the various elements and projects will be defined for each calendar year.

\section{Concluding remarks}

The IGS is continuing its mission of providing highest-quality GNSS data and products in support of the terrestrial 
reference frame; Earth observations and research; positioning, navigation and timing; and other applications that benefit society. The changing landscape of global navigation satellite systems necessitates that the IGS become even more involved with international developments. Long-standing activities are being consolidated and new directions defined. This is documented and supported by the recently developed IGS Strategic Plan 2008-2012.

Acknowledgments The continuing contribution of very many individuals from many organisations world-wide to maintaining the high quality of the IGS products is gratefully acknowledged.

\section{References}

Beutler G, Rothacher M, Schaer S, Springer TA, Kouba J, Neilan RE (1999) The International GPS Service (IGS): an interdisciplinary service in support of earth sciences. Adv Space Res 23:631-635. doi:10.1016/S0273-1177(99)00160-X

Beutler G, Moore AW, Mueller II (2008) The International Global Navigation Satellite Systems (GNSS) Service: developments and achievements (this issue)
Dow JM, Gendt G, Moore A, Neilan RE, Weber R (2004) The International GPS Service-what's next? 10th anniversary assembly charts future directions. In: Proceedings of ION GNSS 2004, Long Beach, CA, USA, 21-24 September, 1741-1748

Dow JM, Neilan RE, Gendt G (2005) The International GPS Service: celebrating the 10th anniversary and looking to the next decade. Adv Space Res 36:320-326. doi:10.1016/j.asr.2005.05.125

Dow JM, Neilan RE, Weber R, Gendt G (2007) Galileo and the IGS: Taking advantage of multiple GNSS constellations. Adv Space Res 39:1545-1551. doi:10.1016/j.asr.2007.04.064

Gendt GS, Rothacher M, GGSP Prototype Team (2007) Realisation and maintenance of the Galileo Terrestrial Reference Frame (GTRF). In: Proceedings of 1st colloquium on scientific and fundamental aspects of the Galileo programme, Toulouse, France, 1-4 October GGOS (2008) http://www.ggos.org

IAG (2008) http://www.iag-aig.org

IERS (2008) http://www.iers.org

IGS (2008) http://igs.org

IGSRT (2008) http://www.rtigs.net

PNT (2008) http://pnt.gov

Slater JA, Weber R, Fragner D (2004) The IGS GLONASS Pilot Project-transitioning an experiment into an operational GNSS service. In: Proceedings of ION GNSS 2004, Long Beach, CA, USA, 21-24 September, 1749-1757

UNOOSA (2008) International Committee on GNSS (ICG) website: http://www.unoosa.org/oosa/en/SAP/gnss/icg.html 